\title{
Pulverisation of calcified and non-calcified gall bladder stones: extracorporeal shock wave lithotripsy used alone
}

Department of Endoscopic Surgery, University Hospital of Hamburg, Germany N Soehendra V-C Nam K F Binmoeller H Koch $S$ Bohnacker H W Schreiber

Correspondence to: Dr N Soehendra, Departmen of Endoscopic Surgery, University Hospital, Martinistrasse 52, 2000 Hamburg 20, Germany. Accepted for publication 26 July 1993

\author{
N Soehendra, V-C Nam, K F Binmoeller, H Koch, S Bohnacker, H W Schreiber
}

\begin{abstract}
Using a modified electromagnetic lithotripter (Siemens), extracorporeal shock wave lithotripsy (ESWL) was performed in 260 patients with gall bladder stones. Exclusion criteria for treatment were a non-functioning gall bladder, subcostal gall bladder location, and multiple stones occupying more than three quarters of the gall bladder volume. Stone pulverisation was the end point of ESWL. The number of shock wave discharges and sessions was not limited. Pulverisation was achieved in 250 patients $(96 \cdot 1 \%)$ after a median of three ESWL sessions (range 1-21). The number of sessions required depended upon stone composition and burden. More than three sessions were required in $60.2 \%$ of patients with calcified stones compared with $35.9 \%$ of patients with non-calcified stones $(p<0.001) .65 .8 \%$ of patients with stones measuring more than $\mathbf{3 0}$ $\mathrm{mm}$ in total diameter required more than three sessions compared with $42.9 \%$ of patients with a stone burden less than $30 \mathrm{~mm}(\mathbf{p}<0.01)$. At 18-24 (8-12) months follow up, stone clearance was achieved in $94.3 \%(80.4 \%)$ of patients with non-calcified stones, compared with $89.5 \%$ $(\mathbf{7 6} .8 \%)$ in patients with calcified stones and in $75 \%(71.4 \%)$ of patients with a total stone diameter more than $30 \mathrm{~mm}$ compared with $95.7 \%(80.4 \%)$ for patients with a total stone diameter less than $30 \mathrm{~mm}(p<0.05)$. ESWL related complications (gross haematuria) occurred in three patients. Thirty six $(13.8 \%)$ patients experienced biliary colic; four had cholecystectomy, and five endoscopic papillotomy because of common bile duct obstruction. Stone recurrence was seen in $5 \cdot 3 \%$ of patients over a follow up period of up to two years (median 16.6 months).

(Gut 1994; 35: 417-422)
\end{abstract}

The currently practised strategy for extracorporeal shock wave lithotripsy (ESWL) treatment of gall bladder stones evolved from the initial experience with the first generation lithotripter from Dornier.' Fragmentation of stones was established as the end point of ESWL to minimise the burden and risks of treatment. The procedure was cumbersome (performed in a water bath), and painful, requiring general anaesthesia or heavy sedation. ESWL was therefore limited to a maximum of two sessions or a maximum of 1600 discharges. Furthermore, stones numbering more than three or exceeding a total diameter of $30 \mathrm{~mm}$ were excluded. To achieve clearance of stone fragments, it was necessary to complement ESWL with oral disso- lution treatment. As oral dissolution treatment was largely ineffective against non-cholesterol gall stones, ESWL was restricted to radiolucent stones. As a result, ESWL proved to be suitable for no more than $15-25 \%$ of patients with gall bladder stones. ${ }^{23}$ This was even further reduced to under $10 \%$ when computed tomography was used to select non-cholesterol stones. ${ }^{45}$

Significant advances in ESWL technology since its introduction in 1985 made us question the validity of the treatment strategy. Both newer generation electromagnetic and piezoelectric machines have been shown to be significantly better tolerated..$^{6-8}$ If current ESWL technology permits treatment without analgesia and severe side effects, an arbitrary limitation to the number of discharges applied and treatment sessions may not be necessary. This has not been investigated, however, in animal studies so far.

Experimental studies have shown that all gall stones can be fragmented by ESWL. The efficacy of fragmentation depended mainly upon the stone burden (size and number); larger and multiple stones required more shockwave discharges to achieve disintegration. ${ }^{9-12}$ Thus, stones greater than $30 \mathrm{~mm}$ in diameter and multiple stones can be fragmented, provided an adequate number of discharges are applied. Further, clinical studies have shown that stone fragment size is the critical determinant of clearance rate. ${ }^{2713} \mathrm{We}$ hypothesised that if gall stones could be maximally disintegrated ('pulverised'), spontaneous clearance may be possible, obviating the need for adjuvant chemolysis. This would permit the inclusion of calcified stones, which would further increase the number of patients eligible for ESWL treatment.

Using a modified electromagnetic ESWL machine, we applied this strategy and report our results in the first 260 patients.

\section{Methods}

\section{PATIENTS}

Between January 1990 and December 1991, 558 patients with symptomatic gall stones were referred to our department of ESWL treatment. Of these, $88(15 \cdot 7 \%)$ were not eligible for ESWL treatment according to the exclusion criteria (Table I). To assess gall bladder function, gall bladder volume was measured by ultrasound before and after a fatty meal; a functional gall bladder was defined as a volume reduction of at least $30 \% .{ }^{14}$ The exclusion of patients with stones occupying more than $75 \%$ of the gall bladder volume was based upon previous experience with combined ESWL and transpapillary contact 
TABLE I Number of patients excluded according to exclusion criteria

\begin{tabular}{lrr}
\hline Exclusion criteria & No & $\%^{\star}$ \\
\hline Stone(s) occupying more than $75 \%$ of gall & & \\
bladder volume & 58 & $10 \cdot 4$ \\
Non-functional gall bladder & 22 & $3 \cdot 9$ \\
Subcostal location of gall bladder & 8 & $1 \cdot 4$ \\
Total & 88 & $15 \cdot 7$ \\
\hline
\end{tabular}

$\star$ Based on total number of referred patients $(n=558)$.

chemolysis using methyl-tert-butyl-ether. ${ }^{15}$ Total stone diameter was measured by ultrasound in a fasting state. Preselection occurred due to preliminary screening by the referring physician; patients with a negative oral or intravenous cholecystogram, coagulation disorder, or pregnancy were not referred.

Of the 470 patients who were suitable for ESWL, 265 patients received ESWL treatment (the remaining patients are on the waiting list for treatment). Five patients stopped treatment before pulverisation could be achieved because of recurrent pain; all opted for laparoscopic cholecystectomy. These patients were excluded from the study, leaving 260 patients for study analysis. There were 163 women and 97 men with a median age of 54 years (range 18-87). All patients who were treated gave informed consent regarding the indication for and risks of treatment and were informed about alternative treatments including laparoscopic cholecystectomy.

\section{STONE CHARACTERISTICS}

Stones were characterised according to findings on ultrasonography, oral or intravenous cholecystography and computed tomography.

Calcification was additionally determined by computed tomography. Some 148 patients (56.9\%) had non-calcified stones and $112(43 \cdot 1 \%)$ calcified stones. Of the group with non-calcified stones, 71 patients $(27 \cdot 3 \%$ of total number) had solitary stones. Solitary stones measured up to 20 $\mathrm{mm}$ in 49 patients, $21-30 \mathrm{~mm}$ in 19 patients, and greater than $30 \mathrm{~mm}$ in three patients. Twenty eight patients $(10 \cdot 8 \%)$ had $2-3$ stones (10 with a total diameter of more than $30 \mathrm{~mm}$ ), and 49 patients (18.8\%) had more than three stones (16 with a total diameter of more than $30 \mathrm{~mm}$ ).

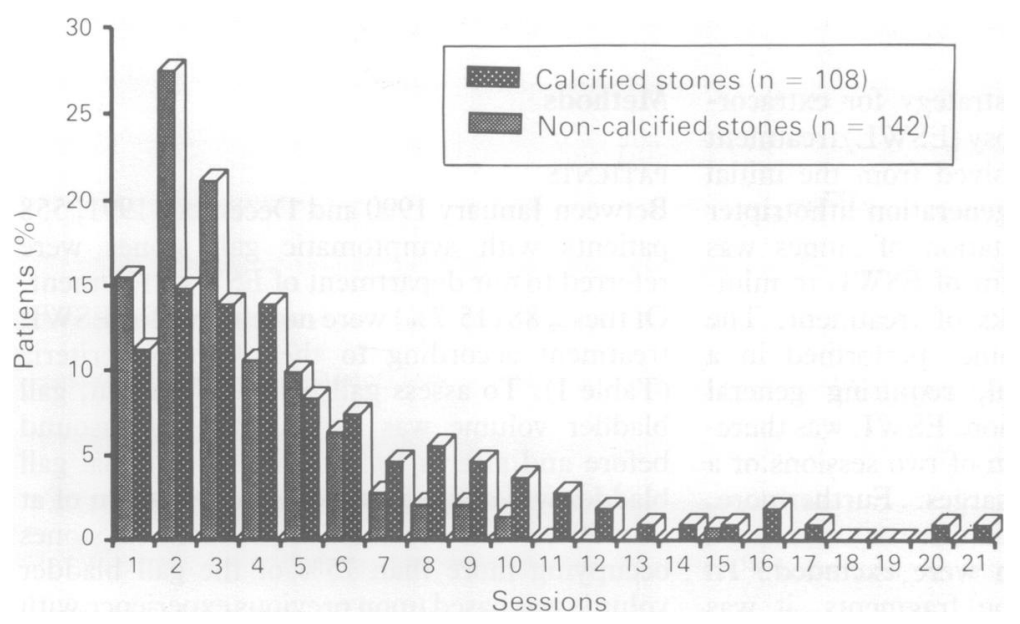

Figure 1: Distribution of number of sessions to achieve pulverisation.
Of the group with calcified stones, 52 patients (20\%) of total number) had solitary stones. These measured up to $20 \mathrm{~mm}$ in 32 patients, $21-$ $30 \mathrm{~mm}$ in 15 patients, and greater than $30 \mathrm{~mm}$ in five patients. Twenty one patients $(8 \cdot 1 \%)$ had two to three stones ( 4 with a total diameter of more than $30 \mathrm{~mm}$ ) and 39 patients $(15 \%)$ had more than three stones (seven with a total diameter of more than $30 \mathrm{~mm}$ ). Stone diameter was determined by ultrasonography; for multiple stones the composite diameter was measured.

\section{TREATMENT PROTOCOL}

No adjuvant treatment was given. Patients were initially treated in hospital on a daily basis for a maximum duration of seven days and thereafter as outpatients on a weekly basis. Pulverisation was sonographically defined by the absence of any measurable stone fragment and any single echo shadow. After reaching pulverisation, follow up ultrasound examination was performed every one to three months using the Sonoline SL (Siemens AG, Erlangen, Germany) with an ultrasound scanner frequency of 3.5 or $5 \mathrm{MHz}$. ESWL was repeated if stone fragments were detected. 'Stone free' was defined as the absence of stone fragments or sludge. This was verified at a different date by an independent physician experienced in sonography. After that ultrasound examination was performed at intervals of three to six months. Examinations were carried out in the upright, supine, and left lateral decubitus positions.

Laboratory tests including white blood cell count, haemoglobin, creatinine, bilirubin, liver enzymes (alkaline phosphatase, $\gamma$-glutamyltransferase, transaminases), and pancreatic enzymes (amylase and lipase) were obtained in patients who developed abdominal pain during the study. Patients suspected of having common bile duct obstruction or biliary pancreatitis had endoscopic retrograde cholangiopancreatography and, when indicated, papillotomy with stone extraction was performed.

\section{EXTRACORPOREAL SHOCK WAVE LITHOTRIPSY}

ESWL was performed with a prototype 'Lithostar' lithotripter (Siemens AG, Erlangen, Germany). The prototype device differed from the commercially available model in the control panel and table construction; this permitted easier targeting of stones. Shock waves were produced by electromagnetic generator and focused with an acoustical lens. Gall bladder stones were located by a $3.5 \mathrm{MHz}$ in line ultrasound probe built into the shock wave overhead module, which permitted continuous real time monitoring of the procedure. Both the table and shock wave overhead module could be electronically steered in all directions to permit optimal targeting of the gall stone. The shock wave energy could be varied in stages from 1 to 9 , which correlated with a pressure in the focal point of 23 to $70 \mathrm{MPa} .{ }^{16}$ The number of discharges applied/session was determined by patient tolerance and contractile state of the gall bladder. On average 4000 discharges/session were applied at a frequency of $2 /$ second; dis- 
TABLE II Stone free rates of uncalcified stones according to size and number of stones

\begin{tabular}{lclllll}
\hline & $\begin{array}{l}0-2 \text { months } \\
n / n(t)(\%)\end{array}$ & $\begin{array}{l}2-4 \text { months } \\
n / n(t)(\%)\end{array}$ & $\begin{array}{l}4-8 \text { months } \\
n / n(t)(\%)\end{array}$ & $\begin{array}{l}8-12 \text { months } \\
n / n(t)(\%)\end{array}$ & $\begin{array}{l}12-18 \text { months } \\
n / n(t)(\%)\end{array}$ & $\begin{array}{l}18-24 \text { months } \\
n / n(t)(\%)\end{array}$ \\
\hline Solitary 1-20 mm & $27 / 49(55 \cdot 1)$ & $35 / 44(79 \cdot 5)$ & $32 / 37(86 \cdot 5)$ & $28 / 31(90 \cdot 3)$ & $21 / 21(100)$ & $13 / 13(100)$ \\
Solitary 21-30 mm & $10 / 19(52 \cdot 6)$ & $12 / 18(66 \cdot 7)$ & $14 / 16(87 \cdot 5)$ & $14 / 15(93 \cdot 3)$ & $11 / 11(100)$ & $7 / 7(100)$ \\
Multiple 2-3, <30 mm & $8 / 18(44 \cdot 4)$ & $9 / 16(56 \cdot 3)$ & $8 / 15(53 \cdot 3)$ & $8 / 11(72 \cdot 7)$ & $9 / 10(90)$ & $2 / 2(100)$ \\
Subtotal & $45 / 86(52 \cdot 3)$ & $56 / 78(71 \cdot 8)$ & $54 / 68(79 \cdot 4)$ & $50 / 57(87 \cdot 7)$ & $41 / 42(97 \cdot 6)$ & $22 / 22(100)$ \\
Multiple 2-3, >30 mm & $1 / 10(10)$ & $3 / 10(30 \cdot 0)$ & $2 / 6(33 \cdot 3)$ & $3 / 6(50)$ & $3 / 6(50)$ & $2 / 4(50)$ \\
Solitary >30 mm & $1 / 3(33 \cdot 3)$ & $1 / 3(33 \cdot 3)$ & $1 / 3(33 \cdot 3)$ & $0 / 2(0)$ & $0 / 2(0)$ & $0 / 0$ \\
Multiple more than 3 & $18 / 49(36 \cdot 7)$ & $22 / 48(45 \cdot 8)$ & $31 / 45(68 \cdot 9)$ & $25 / 32(78 \cdot 1)$ & $19 / 22(86 \cdot 4)$ & $9 / 9(100)$ \\
Total & $65 / 148(43 \cdot 9)$ & $\mathbf{8 2 / 1 3 9 ( 5 9 \cdot 0 )}$ & $\mathbf{8 8 / 1 2 2 ( 7 2 \cdot 1 )}$ & $78 / 97(80 \cdot 4)$ & $63 / 72(87 \cdot 5)$ & $33 / 35(94 \cdot 3)$ \\
\hline
\end{tabular}

$\mathrm{n}=$ number of patients stone-free; $\mathrm{n}(\mathrm{t})=$ total number of patients during the respective follow up period; ${ }^{\star} 0-2$ months indicates an interval up to two months.

TABLE III Stone free rates of calcified stones according to size and number of stones

\begin{tabular}{lclllll}
\hline & $\begin{array}{l}0-2 \text { months } \\
n / n(t)(\%)\end{array}$ & $\begin{array}{l}2-4 \text { months } \\
n / n(t)(\%)\end{array}$ & $\begin{array}{l}4-8 \text { months } \\
n / n(t)(\%)\end{array}$ & $\begin{array}{l}8-12 \text { months } \\
n / n(t)(\%)\end{array}$ & $\begin{array}{l}12-18 \text { months } \\
n / n(t)(\%)\end{array}$ & $\begin{array}{l}18-24 \text { months } \\
n / n(t)(\%)\end{array}$ \\
\hline Solitary 1-20 mm & $16 / 32(50)$ & $16 / 30(53 \cdot 3)$ & $21 / 29(72 \cdot 4)$ & $18 / 21(85 \cdot 7)$ & $12 / 15(80)$ & $6 / 7(85 \cdot 7)$ \\
Solitary 21-30 mm & $7 / 15(46 \cdot 7)$ & $11 / 14(78 \cdot 6)$ & $11 / 12(91 \cdot 7)$ & $9 / 9(100)$ & $7 / 7(100)$ & $2 / 2(100)$ \\
Solitary >30 mm & $0 / 5(0)$ & $2 / 5(40)$ & $2 / 4(50)$ & $1 / 2(50)$ & $0 / 1(0)$ & $0 / 0$ \\
Multiple 2-3 & $7 / 21(33 \cdot 3)$ & $9 / 16(56 \cdot 3)$ & $9 / 14(64 \cdot 3)$ & $7 / 10(70)$ & $7 / 9(77 \cdot 8)$ & $3 / 3(100)$ \\
Multiple more than 3 & $17 / 39(43 \cdot 6)$ & $18 / 37(48 \cdot 6)$ & $23 / 35(65 \cdot 7)$ & $18 / 27(66 \cdot 7)$ & $15 / 20(75 \cdot 0)$ & $6 / 7(85 \cdot 7)$ \\
Total & $47 / 112(42)$ & $56 / 102(54 \cdot 9)$ & $66 / 94(70 \cdot 2)$ & $53 / 69(76 \cdot 8)$ & $41 / 52(78 \cdot 8)$ & $17 / 19(89 \cdot 5)$ \\
\hline
\end{tabular}

${ }^{\star} 0-2$ months indicates an interval up to two months; abbreviations as in Table II.

charges were not triggered by heart frequency. There was no upper limit to the total number of discharges. The energy level of discharges was progressively increased during each session to the maximum level tolerated by the patient. The average power setting was level $7 ; 75 \%$ of patients tolerated the maximum level of energy (level 9) without pain. Patients were treated in the supine or left lateral decubitus position. All patients tolerated ESWL treatment well and none of the patients required analgesics.

\section{STATISTICAL ANALYSIS}

The statistical significance of differences was assessed with the $\chi^{2}$ test. $p$ Values less than 0.05 were regarded as significant. The number of ESWL sessions and shock waves was expressed as median values with ranges.

\section{Results}

Gall stones could be pulverised in 250 of 260 patients $(96 \cdot 1 \%)$ after a median of three ESWL sessions (range 1-21). In the remaining 10 patients only fragmentation of stones could be achieved (seven patients had stones measuring more than $30 \mathrm{~mm}$ in total diameter, of which two were calcified); a median number of $10 \mathrm{ESWL}$ sessions (range 3-24) were performed. Treatment was stopped because of poor response to shock wave treatment. For the entire patient collective, a median number of 4000 (range 1000-16000) discharges were applied/session. The median number of shockwaves applied/ patient was 14000 (range 4000-26000). The time required for a single treatment session of 4000 discharges was 60 minutes. All patients who had biliary symptoms during the treatment period reported resolution or a considerable reduction of symptoms that temporally correlated with pulverisation of stones. Figure 1 shows the distribution of number of sessions required to achieve pulverisation in 250 patients with calcified and non-calcified stones. Calcified stones required significantly more sessions to achieve pulverisation compared with non-calcified stones. More than three treatment sessions were required in 65 of 108 patients $(60.2 \%)$ and 51 of 142 patients $(35.9 \%)$ of patients with calcified and non-calcified stones, respectively $(\mathrm{p}<0.001)$.

Twelve of 24 patients ( $50 \%$ ) with non-calcified stones measuring greater than $30 \mathrm{~mm}$ in total diameter required more than three treatment sessions to achieve pulverisation compared with 39 of 118 patients $(33 \cdot 1 \%)$ with a total stone diameter less than $30 \mathrm{~mm}$ (not significant, $\mathrm{p}>0.05)$. Thirteen of 14 patients $(92.9 \%)$ with calcified stones measuring greater than $30 \mathrm{~mm}$ in total diameter required more than three treatment sessions compared with 52 of 94 patients $(55 \cdot 3 \%)$ with a total stone diameter less than 30 $\mathrm{mm}(\mathrm{p}<0.01)$. In total $65.8 \%(25 / 38)$ of patients with a total stone diameter of more than $30 \mathrm{~mm}$ required more than three sessions compared with $42.9 \%(91 / 212)$ of patients with a total stone diameter of less than $30 \mathrm{~mm}(\mathrm{p}<0 \cdot 01)$. Table II shows clearance rates according to stone characteristics and period of follow up after the first ESWL session. The observation intervals and stone characteristics were adapted from the Munich study ${ }^{2}$ for the purpose of comparison.

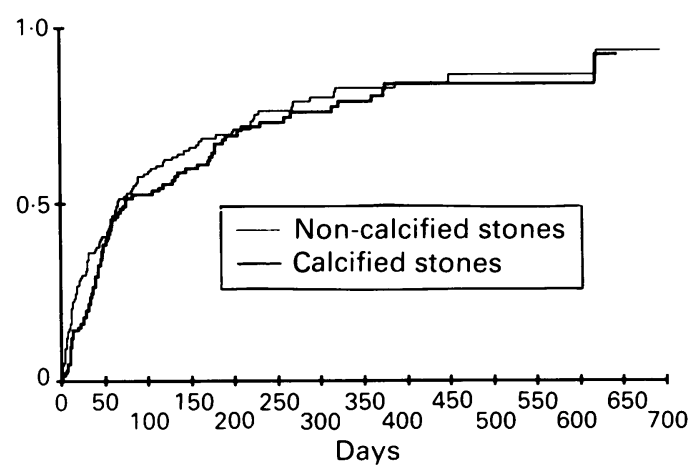

Figure 2: Stone free rates of patients with uncalcified and calcified stones. 
TABLE IV Stone free rates of gall stones with a total diameter greater than $30 \mathrm{~mm}$

\begin{tabular}{lllllll}
\hline & $0-2$ months & $\begin{array}{l}2-4 \text { months } \\
n / n(t)(\%)\end{array}$ & $\begin{array}{l}4-8 \text { months } \\
n / n(t)(\%)\end{array}$ & $\begin{array}{l}8-12 \text { months } \\
n / n(t)(\%)\end{array}$ & $\begin{array}{l}12-18 \text { months } \\
n / n(t)(\%)\end{array}$ & $\begin{array}{l}18-24 \text { months } \\
n / n(t)(\%)\end{array}$ \\
\hline$>30 \mathrm{~mm}$, uncalcified & $6 / 29(20 \cdot 7)$ & $12 / 29(41 \cdot 4)$ & $15 / 24(62 \cdot 5)$ & $13 / 19(68 \cdot 4)$ & $10 / 15(66 \cdot 7)$ & $4 / 6(66 \cdot 7)$ \\
$>30 \mathrm{~mm}$, calcified & $3 / 16(18 \cdot 8)$ & $5 / 12(41 \cdot 7)$ & $7 / 11(63 \cdot 6)$ & $7 / 9(77 \cdot 8)$ & $6 / 7(85 \cdot 7)$ & $2 / 2(100)$ \\
Total & $9 / 45(20)$ & $17 / 41(41 \cdot 5)$ & $22 / 35(62 \cdot 9)$ & $20 / 28(71 \cdot 4)$ & $16 / 22(72 \cdot 7)$ & $6 / 8(75)$ \\
\hline
\end{tabular}

$\star 0-2$ months indicates an interval up to two months; abbreviations as in Table II.

TABLE V Stone free rates of gall stones with a total diameter less than $30 \mathrm{~mm}$

\begin{tabular}{lclllll}
\hline & $\begin{array}{l}0-2 \text { months } \\
n / n(t)(\%)\end{array}$ & $\begin{array}{l}2-4 \text { months } \\
n / n(t)(\%)\end{array}$ & $\begin{array}{l}4-8 \text { months } \\
n / n(t)(\%)\end{array}$ & $\begin{array}{l}8-12 \text { months } \\
n / n(t)(\%)\end{array}$ & $\begin{array}{l}12-18 \text { months } \\
n / n(t)(\%)\end{array}$ & $\begin{array}{l}18-24 \text { months } \\
n / n(t)(\%)\end{array}$ \\
\hline$<30 \mathrm{~mm}$, uncalcified & $59 / 119(49 \cdot 6)$ & $70 / 110(63 \cdot 6)$ & $73 / 98(74 \cdot 5)$ & $65 / 78(83 \cdot 3)$ & $53 / 57(93)$ & $29 / 29(100)$ \\
$<30 \mathrm{~mm}$, calcified & $44 / 96(45 \cdot 8)$ & $51 / 90(56 \cdot 7)$ & $59 / 83(71 \cdot 1)$ & $\begin{array}{c}46 / 60(76 \cdot 7) \\
35 / 45(77 \cdot 8)\end{array}$ & $15 / 17(88 \cdot 2)$ \\
Total & $103 / 215(47 \cdot 9)$ & $121 / 200(60 \cdot 5)$ & $132 / 181(72 \cdot 9)$ & $111 / 138(80 \cdot 4)$ & $88 / 102(86 \cdot 3)$ & $44 / 46(95 \cdot 7)$ \\
\hline
\end{tabular}

$\star_{0}$-2 months indicates an interval up to two months; abbreviations as in Table II.

Tables II, III, IV, and V give the results for calcified stones, stones larger than $30 \mathrm{~mm}$ in total diameter, and multiple stones (more than three), which were not included in the Munich study. The data include patients in whom pulverisation was not achieved. Figure 2 shows Kaplan/Meier graph representation of stone free rates of patients with uncalcified and calcified stones. The numbers of stone free patients at $6,12,18$, and 24 months were 157, 181, 186, and 188, respectively. The numbers of stone free patients seen for $<6,6-12,12-18$, and 18-24 months were $88,64,75$, and 23 , respectively (median $9 \cdot 4$ months).

\section{ADVERSE EVENTS}

During a follow up period of up to two years (mean 11.8 months, median 11.8 months, range $0.4-24 \cdot 0) 36$ patients (13.8\%) experienced biliary colic. Four patients had cholecystectomy, two because of recurrent colic and two because of acute cholecystitis. Of the remaining 32 patients 12 had laboratory evidence of cholestasis, of whom two also had an increase in pancreatic enzymes. If five of these patients an endoscopic retrograde cholangiopancreatography and papillotomy was performed, whereby stone debris was extracted in three cases. Seven patients could be managed conservatively with full resolution of cholestatis within a few days. Gross haematuria was seen in three patients during our initial experience with ESWL and was not seen later. Based on clinical parameters, there was no other evidence of tissue damage. Of the 39 patients who had complications, 30 could be successfully treated conservatively. Cystic duct obstruction was not seen.

\section{RECURRENCE}

We defined a recurrence as detection of stones in a previous stone free patient on follow up ultrasound examination. Of 188 patients who became stone free, $10(5 \cdot 3 \%)$ were found to have gravel like stones on follow up ultrasound examination. No correlation with previous stone characteristics was seen. The median observation period was 16.6 months (range 11.8-24). Of these, the gall bladder could be cleared of stones in two patients after one and six further ESWL sessions, respectively.

\section{Discussion}

In our study we could achieve pulverisation of gall stones in $96.1 \%$ of patients regardless of size, number or composition of gall stones using a modified electromagnetic lithotripter. Sedation or analgesic treatment was not required in any of the patients.

After pulverisation, spontaneous clearance of stone debris occurred without adjuvant oral bile acid treatment. This confirms previous studies, which have shown that the clearance rates are proportionate to the size of fragments. Sackmann et $\mathrm{al}^{217}$ showed that for fragments less than $3 \mathrm{~mm}$ in size the clearance rate at one year was $70 \%$, whereas for fragments larger than $5 \mathrm{~mm}$ the clearance rate was only $30 \%$ for the same time period. Ponchon $e t a l^{13}$ found that patients with complete fragmentation had significantly higher clearance rates compared with patients with partial fragmentation (55 v 0\% after six months; $80 v 29 \%$ after nine months; $90 v 33 \%$ after 12 months). Other authors have also suggested that smaller fragments clear more rapidly. ${ }^{78}$

In our study, the rapidity with which pulverisation of gall stones was achieved depended upon the stone composition and burden. Calcified stones required significantly more sessions to achieve pulverisation compared with noncalcified stones. The composition of the stone, however, did not significantly affect clearance rates. Apparently, once pulverisation is achieved, there is no difference in the clearance rates between non-calcified and calcified stones. In contrast, other authors have found clearance rates to differ when fragmentation was the end point of ESWL treatment. Rawat and Burhenne ${ }^{19}$ have shown that calcified stones cleared more slowly from the gall bladder than noncalcified stones using an electromagnetic device. Ell $e t a l,{ }^{5}$ found that the rate of complete stone disappearance was higher for non-calcified stones than for calcified stones using a second generation piezoelectric lithotripter.

Several studies included partially calcified stones in the treatment protocol. Sackmann $e t a l^{20}$ recently reported the results of ESWL for gall bladder calculi with a radio-opaque rim comparing three different lithotripsy treatment modalities. Higher clearance rates were found for stones less than or equal to $3 \mathrm{~mm}$ in diameter compared with larger fragments. Other studies did not separately analyse clearance rates for 
calcified stones. ${ }^{2819}$ Albert et $a l^{21}$ reported clearance of a densely calcified stone within one week of a single session of ESWL. The stone was fragmented to particles of less than 1-2 mm, which presumably accounts for this rapid clearance.

In our study calcification was primarily detected on plain radiographs; only $15 \%$ of patients with calcified stones were diagnosed by computed tomography. A comparison of our data with those of other studies that have evaluated the efficacy of ESWL for stones of variable calcium content ${ }^{520}$ is difficult because the end point of ESWL treatment in these studies was fragmentation.

Patients with stones measuring more than 30 $\mathrm{mm}$ required significantly more sessions to pulverise stones compared with patients with stones less than $30 \mathrm{~mm}$. It is also noteworthy that patients with stones larger than $30 \mathrm{~mm}$ in total diameter showed lower clearance rates compared with those with stones less than $30 \mathrm{~mm}$ (75 v $95.7 \%$ at $18-24$ months; $\mathrm{p}<0.05)$. Using a piezoelectric lithotripter, Darzi et $a l^{6}$ extended their selection criteria in a study of 124 patients to include larger and calcified stones and reported successful fragmentation in only four of eight patients with stones larger than $30 \mathrm{~mm}$. None of the patients achieved complete gall bladder clearance. In this study 6000 shock waves were applied/session up to a maximum of six sessions, but the end point of ESWL was fragmentation less than $4 \mathrm{~mm}$, compared with pulverisation in our study. Using an electromagnetic lithotripter (Siemens Lithostar Plus), Meiser et al ${ }^{22}$ extended their selection criteria to include patients with stones up to $38 \mathrm{~mm}$ in size and more than three stones. Seven of 27 patients with three or more stones became stone free over a follow up period of at least 12 months. Although other authors have included some patients with a total stone size greater than $30 \mathrm{~mm}$, this variable has not been separately analysed..$^{623}$

The role of the bile acid ursodiol as adjuvant treatment after ESWL is still a subject of debate. Bile acids in conjunction with ESWL seem to be clearly superior to bile acid treatment alone. ${ }^{24} 25$ The American national biliary lithotripsy study, which included 600 patients with 1-3 radiolucent or slightly calcified (less than $3 \mathrm{~mm}$ nidus or rim calcification) gall stones $5-30 \mathrm{~mm}$ in diameter, showed that ESWL with ursodiol was more effective than ESWL alone. ${ }^{26}$ In an initial study of similar design by Torres et $a l^{27}$ no significant difference between the ursodiol and placebo groups was found; however, in a follow up study ${ }^{28}$ the stone free rate at 12 months was noted to be significantly higher for patients with a single, non-calcified stone up to $20 \mathrm{~mm}$ in diameter in patients treated with adjuvant bile acids. Unsatisfactory results with bile acid treatment may be because most gall stones are not pure cholesterol stones. In a study that analysed the faeces of patients during the first three days after ESWL treatment for radiolucent stones, Greiner et $a l^{29}$ found most stone fragments were from mixed stones. Stone fragments measured $0.5-8 \mathrm{~mm}$ in diameter. This study suggests that the clearance of gall stones after ESWL mainly depends upon a functioning gall bladder and sufficiently fine fragmentation.
The Vancouver group was the first to use ESWL as the sole treatment. With a higher number of shock wave discharges (up to 20000), they could disintegrate stones to fragments measuring less than $3 \mathrm{~mm} .{ }^{30}$ The overall stone free rate at 12 months was $61 \%$. The data included patients with calcified and multiple (more than three) stones. The authors concluded that, with an expanded protocol that includes patients with up to six stones and calcified stones, the results of monotherapy were comparable with that of combined ESWL and oral bile acid treatment reported in other centres. The clearance rate, however, for calcified stones in this study was poor (clearance in only two of 17 patients).

We could achieve clearance rates similar to the Munich group without adjuvant bile acid treatment both for non-calcified and calcified stones. For patients with non-calcified stones equal to or less than three in number and $30 \mathrm{~mm}$ in total mass, the Munich group reported stone free rates of $30 \%$ at $0-2$ months, $48 \%$ at $2-4$ months, $63 \%$ at $4-8$ months, $78 \%$ at $8-12$ months, $91 \%$ at 12 18 months, and $93 \%$ at $18-24$ months. ${ }^{2}$ Our results with ESWL as the sole treatment showed significantly more rapid clearance during the first four months and comparable clearance rates thereafter. This can be explained by the fact that pulverisation of stones was the end point of our treatment with ESWL compared with fragmentation by the Munich group. The lower initial stone clearance rate in the Munich study is presumably because of the delayed effect of bile acids on stone dissolution.

We believe that the most critical factor determining ESWL success is the precise targeting of stones or stone fragments. This has been previously shown in experimental studies by Zeman et al. ${ }^{31}$ Both the expertise of the physician performing ESWL and the lithotripter technology available contribute to precise targeting. The Lithostar lithotripter used in this study permitted fine adjustments in both patient and overhead module position to optimise targeting. We believe that this explains why sedation or analgesia was not required in our patients and complications directly attributable to shockwave therapy were so low (gross haematuria occurred in three cases during the initial phase of the study) despite high numbers of discharges up to 16000 discharges/session using an electromagnetic lithotripter.

Acute cholecystitis, bile duct obstruction, and pancreatitis occurred with similar frequency to that reported in other studies. ${ }^{2781723}$ In our study, however, the incidence of biliary colic after ESWL was lower (14\% $v$ an average of $30 \%$ in other studies). This may be explained by the fact that the end point of ESWL in our study was pulverisation compared with fragmentation in other studies.

ESWL is still burdened by the problem of stone recurrence after clearance. Recurrence has been reported in $11 \%$ at 1.5 years without further increase up to three years..$^{32}$ Our recurrence rate was $5.3 \%$ in a follow up period of up to two years (median 16.6 months). No correlation with previous stone characteristics was seen.

In conclusion, this study has shown that, when 
the number of shockwave discharges and sessions are not restricted, ESWL can effectively pulverise gall stones in nearly all patients selected for treatment. A high rate of clearance was achieved without adjuvant bile acid treatment.

1 Sauerbruch T, Delius M, Paumgartner G, Hool J, Weber W, Ippisch E, et al. Fragmentation of gallstones by extracorporeal shock waves. NEngl $\mathcal{M}$ Med 1986; 314: 818-22.

2 Sackmann M, Delius M, Sauerbruch T, Hool J, Weber W, Ippisch E, et al. Shock-wave lithotripsy of gallbladde stones: the first 175 patients. $N$ Engl $\mathcal{F}$ Med 1988; 318 393-7.

3 Brink JA, Simeone JF, Mueller PR, Richter JM, Prien EL, Ferrucci JT. Physical characteristics of gallstones removed at cholecystectomy: Implications for extracorporeal shockwave lithotripsy. AfR Am f Roentgenol 1988; 151: 927-31.

4 Rambow A, Staritz M, Klose P, Thelen M, Friedel N, Rodl W, et al. Extrakorporale Stoßwellenlithotripsie von Gallenet al. Extrakorporale Stoßwellenlithotripsie von GallenWochenschr 1989; 114: 895-8.

5 Ell Ch, Schneider HT, Benninger J, Theobaldy S, Friedel N, Rodl W, et al. Significance of computed tomography for shock-wave therapy of radio-lucent gallbladder stones. Gastroenterology 1991; 101: 1409-16.

6 Darzi A, Tanner WA, Keane FBV. Piezoelectric lithotripsy for gallstones: results of the first hundred patients treated in Dublin. In: Paumgartner G, Sauerbruch T, Sackmann M, Burhenne $\mathrm{HJ}$, eds. Lithotripsy and related techniques for gallstone treatment. St Louis: Morby Year Book, 1991: 73-9. Ell Ch, Kerzel W, Schneider HT, Benninger J, Wirtz P, Domschke W, et al. Piezoelectric lithotripsy: stone disintegration and follow-up results in patients with sympto-
matic gallbladder stones. Gastroenterology 1990; 99: matic gall $1439-44$.

8 Classen M, Cremer M,Faustini S, Meiser G, Zum Buschenfelde $M$, Neuhaus $H$, et al. Electromagnetic shock-wave lithotripsy of gallbladder calculi. Multicentered preliminary report on experience with 276 patients. Hepatogastroenterology 1990; 37: 425-7.

9 Schachler R, Sauerbruch T, Wosiewitz U, Holl J, Hahn D, Denk R, et al. Fragmentation of gallstones using extracorporeal shock waves: an in vitro study. Hepatology 1988; 8:
925-9.

10 Petersen BT, Segura JW, Thistle JL. Gallstones lithotripsy: in vitro comparison of four different shock wave generators. Gastroenterology 1988; 94: A581.

11 Ell Ch, Kerzel W, Langer H, Heyder N, Foerster E, Domschke W. Fragmentation of biliary calculi by means of extracorporeally generated piezoelectric shock waves. 6-10.

12 Albert MB, Fromm H, Shehan CM. Determinants of fragmentation of gallstones with the EDAP LT01 lithotripter: invitro studies of gallstones characteristics. Gastroenterology 1989; 96: A571.

13 Ponchon T, Barkun AN, Pujol B,Mestas JL, Lambert R. Gallstone disappearance after extracorporeal lithotripsy and oral bile acid dissolution. Gastroenterology 1989; 97: 457-63.

14 Janowitz P, Kratzer W, Wechsler JG, Kuhn K, Janowitz A, Swobodnik W. Gallenblasensteinbehandlung mit elektrohydraulischer extrakorporaler Stoßwellenlithotripsie. Dtsch Med Wochenschr 1991; 116: 1297-302.
15 Soehendra N, Schulz H, Nam VC, Maydeo A, Schenkengel JP, Grimm $\mathrm{H}$, et al. ESWL and gallstone dissolution with MTBE via a naso-vesicular catheter. Endoscopy 1990; 22: 176-9.

16 Folberth $W$, Pressure-optimized lithotripsy with the Siemens Lithostar: successful treatment of urinary stones. European Urology 1990; 17: 51-7.

17 Sackmann M, Pauletzki J, Sauerbruch T, Holl J, Schelling G, Paumgartner G. The Munich gallbladder lithotripsy study results of the first 5 years with 711 patients. Ann Intern Med 1991; 114: 290-6.

18 Zeman RK, Al-Kawas F, Benjamin SB. Gallstone lithotripsy: is there still cause for optimism? Radiology 1991; 178: 33-5.

19 Rawat B, Burhenne HJ. Extracorporeal shock wave lithotrips of calcified gallstones. Work in progress. Radiology 1990; 175: $667-70$.

20 Sackmann M, Pauletzki J, Delius M, Holl J, Neubrand M, Sauerbruch $\mathrm{T}$, et al. Noninvasive therepy of gallbladder calculi with a radioopaque rim. Gastroenterology 1992; 102: 988-93.

21 Albert MB, Fromm H, Shehan CM. Densely calcified gallstone treated successfully with piezoelectric lithotripsy. Gastroenterology 1990; 98: 777-9.

22 Meiser G, Heinerman M, Lexer G, Boeckl O. Aggressive extracorporeal shock wave lithotripsy of gall bladder stones within wider treatment criteria: fragmentation rate and early results. Gut 1992; 33: 277-81.

23 den Toom R, Vergunst H, Nijs HG, Brakel K, Lameris JS Terpstra OT. Electromagnetic shockwave litho-tripsy of gallbladder stones: a wide range of inclusion critera. Am f Gastroenterol 1992; 87: 498-503.

24 Tint GS, Dyrszka H, Sanghavi B, Patel G, Patel S, Shefer S, et al. Lithotripsy plus ursodiol is superior to ursodiol alone for cholesterol gallstones. Gastroenterology 1992; 102: 2042-9.

25 Ertan A, Hernandez RE, Campeau RJ, Geshner JR, Litwin MS. Extracorporeal shock-wave lithotripsy and ursodiol versus ursodiol alone in the treatment of gallstones. Gastroenterology 1992; 103: 311-6.

26 Schoenfield LJ, Berci G, Carnovale RL, Casarella W, Caslowitz $\mathrm{P}$, Chumley $\mathrm{D}$, et al. The effect of ursodiol on the efficacy and safety of extracorporeal shock-wave lithotripsy of gallstones. The Dornier national biliary lithotripsy study. NEnglf Med 1990; 323: 1239-45.

27 Torres WE, Steinberg HV, Davis RC, Baumgartner BR Nelson RC, Casarella WJ, et al. Extracorporeal shock wave lithotripsy of gallstones: Results and 6-month follow-up in 141 patients. Radiology 1991; 178: 509-12

28 Torres WE, Baumgartner BR, Nelson RC, Morris SJ. Shock wave lithotripsy of gallstones: results and 12-month followwave lithotripsy of gallstones: results and 12-month

29 Greiner L, Münks C, Heil W, Jakobeit C. Gallbladder stone fragments in feces after biliary extracorporeal shock-wave lithotripsy. Gastroenterology 1990; 98: 1620-4

30 Fache JS, Rawat B, Burhenne HJ. Extracorporeal cholecystolithotripsy without oral chemolitholysis. Radiology 1990; 177: 719-21.

31 Zeman RK, Davros WJ, Garra BS, Goldberg JA, Horii SC, Silverman PM, et al. Relationship between stone motion, targeting, and fragmentation during experimental biliary lithotripsy. Radiology 1990: 176: 125-8.

32 Sackmann M, Ippisch E, Sauerbruch T, Holl J, Brendel W, Paumgartner $\mathrm{G}$. Early gallstone recurrence rate after successful shock wave therapy. Gastroenterology 1990; 98: cessful 